\title{
Letters
}

\section{Changes in attitudes regarding cancer disclosure among medical students at the American University of Beirut}

SIR

The American University of Beirut (AUB) was established in the last decade of the 19 th century and is the only one of three current medical programmes in Lebanon to adopt American curricular standards and English as a language of instruction. A forma course in medical ethics was introduced in 1994, which instructs students in the third year on issues such as truth-telling to patients, within the context of the "paternalism versus autonomy" debate. ${ }^{1-4}$ Changes of attitude toward cancer disclosure following the introduction of that forma course were measured serially in the same class of AUB medical students as they moved from the first to the fourth medical years. In that four-year interval, students graduated from theoretical courses to clinical contact with patients.

Seventy students (median age 21 , $23 \%$ females) were first interviewed in 1995 , of whom $65 \%$ were available for a second interview in 1998. The same questionnaire was used both times, and assessed students' general preference regarding disclosure of cancer diagnosis to the patient ("prefer to tell or not to tell"). A list of patient variables was proposed, and students had to indicate whether they felt a particular variable to be important in deciding whether to disclose for a specific patient. Finally, four statements measuring personal attitudes and perceived norms regarding disclosure were also assessed.

A large majority ( $84 \%$ ) of those surveyed in 1995 preferred to disclose the cancer diagnosis to the patient directly, and that proportion remained high $(86 \%)$ as they moved to their fourth year. Patients' characteristics thought at both points to be important in adopting a disclosure decision were mostly related to emotional stability, expressed desire to be told the truth, and expected survival time. Characteristics which were not important at both measurements were social status and gender. None of the students perceived patients' religious beliefs to be important at baseline versus $11.5 \%$ at follow-up ( $p=0.02)$. At baseline, $74 \%$ thought that patients' medical awareness was important versus $57 \%$ at follow-up ( $p=0.10)$.

The proportion of students who believed that cancer patients consider deception as beneficial decreased from $60.5 \%$ to $31 \%(\mathrm{p}=0.005)$. Those who expect their physician to deceive them if they were cancer patients decreased from $48 \%$ to $18 \%(p=0.002)$. Those who believe they would know what is in their "patient's best interest" and act accordingly decreased from $78 \%$ to $57 \%(p=0.033)$. Finally, the proportion of those who perceived physicians to resort to deception "often" with their patients increased from $16 \%$ to $54 \%(\mathrm{p}<0.001)$.

In Lebanon, paternalistic attitudes favouring concealment of serious diagnoses have prevailed among physicians. Both physicians and the public at large traditionally assumed that direct disclosure of cancer diagnosis to the patient might be detrimental. Recent studies have challenged those assumptions and indicated that expectations may be changing in Lebanon as they have elsewhere. ${ }^{56}$ In this brief report, we show that as medical students mature they become more able to put aside their, usually negative, prejudice about the patient's own view of what is best for him or her, when deciding whether to disclose or not. This may indicate that over time students become more aware of the psychological turmoil which accompanies cancer disclosure, where objective knowledge is less important than coping strategies. The increasing realisation that patients do not always perceive deception to be beneficial, that physicians cannot alone determine the best interest of the patient, and that a large number of practising physicians still resort to deception are interesting findings. They show that this generation of young Lebanese graduates is turning away from the real or perceived paternalistic attitude of more senior physicians and adopting attitudes more respectful of the patient's autonomy, needs and right to know. It will be important to evaluate how much of this nuanced "pro-disclosure" attitude carries over into their "real-life" professional practice in the future.

\section{References}

1 Haley HB, Huynh H, Paiva REA, Juan IR. Students' attitudes toward cancer: changes in medical school. Fournal of Medical Education 1977;52:500-7.

2 Novack DH, Plumer R, Smith RL, Ochitill H, Morrow GR, Bennet JM. Changes in physicians' attitudes toward telling the cancer patient. Fournal of the American Medical Association 1979;241:897-900.

3 Cohen RE, Ruckdeschel JC, Blanchard CG, Rohrbaugh M, Horton J. Attitudes towards cancer: a comparative analysis of cancer patients, medical students, medical residents, physicians and cancer educators. Cancer 1982;50: 1218-23.

4 Hays DM, Hoffman KI, Williams KO, Miller R. Effects of intensive clinical exposure on attitudes of medical students toward cancer-related problems. Cancer 1985;55:636-42.

5 Hamadeh GN, Adib SM. Cancer truth disclosure by Lebanese doctors. Social Science and Medicine 1998;47:1289-94.

6 Adib SM, Hamadeh GN. Attitudes regarding disclosure of serious illness in the Lebanese public. Fournal of Medical Ethics 1999;25:399-403.

GHASSAN N HAMADEH, MD Department of Family Medicine, American University of Beirut Beirut, Lebanon.

SALIM M ADIB, MD, DRPH, Department of Community Medicine, Kuwait University, Kuwait 


\section{Jehovah's Witnesses and blood transfusions}

SIR

I have been following with interest the series of articles in the fournal of Medical Ethics on the subject of Jehovah's Witnesses and the refusal of blood transfusions. There are a couple of aspects which have not been covered and which I would like to raise.

Most of the discussion has centred around adult Jehovah's Witnesses. However, where children are involved the issues become more complex and emotive. I feel that there is a need to examine the rights and responsibilities of parents in the making of life and death decisions on behalf of their children. Also, there is the question of the extent to which the child should be consulted.

If the decision is made to give child a blood transfusion against his or her parents' wishes, the long term psychological effect on the child should also be taken into account. Depending upon the age of the child, he may also have strong views on the subject as result of the teaching he has received.

In Jehovah's Witness publications, the administration of an unwanted transfusion is likened to assault or rape. Taking blood is presented as disobedience to a very importan divine command. Consequently, it is worth considering how children/ teenagers may view this treatment and also how they may view themselves after having (albeit unwillingly) broken God's law as they see it.

So, while the medical personnel involved may be convinced they have saved the child's life, at the same time consideration needs to be given to the differing perspective of the child himself, his family and his religious community. I wonder whether there have been any studies done of the long term psychological effects on those who received transfusions as children.

Another aspect which has not been covered in the discussion to date is the feelings of the nurses involved in the administration of the transfusion. Traditionally, paediatric nurses have worked with parents in caring for their children while in hospital. Therefore, handling a situation in which the wishes of the parents and child are being overridden is difficult. I read the report of a case in which the nurse administering the transfusion was convinced that it was necessary to save the child's life. At the same time, she was deeply distressed by the obvious distress of the child and his parents. This highlights the need for support for nurses in such situations.

I feel that the discussion in the fournal of Medical Ethics has been very helpful in highlighting the variety of views current among Jehovah's Witnesses on the subject of treatments containing blood. I hope that it will help to make both doctors and Jehovah's Witness patients more aware of the options open to them. Translating this into the best possible care for each individual Witness patient may be more difficult, but this is certainly a step in the right direction.

HELEN M DESCOMBES (MRS)

129 Ballards Rd

Dagenham, Essex RM10 9AR

\section{Hospitalised mentally ill patients vote in} Israel

sir

This is the third time hospitalised mentally ill patients have voted in Israeli elections.

In 1996 the law was changed so that patients, including those in psychiatric hospitals, could participate in elections while hospitalised.

Until that year, hospitalised patients could participate in elections only if released from the hospital to vote at their local polling stations.

The ability of mentally ill patients to participate in the democratic process has aroused interest over a long period of time.

In Israel, the right to vote, granted in 1996, raised questions regarding whether the character of their vote would differ from that of the general society or would be apportioned according to the normal distribution of the vote of the citizenry. ${ }^{2}$

In the 1999 elections, patients again participated; however, their voting rate was conspicuously lower than that of the general population: in a psychiatric hospital in the Tel Aviv area, 29\% of the hospitalised patients voted, compared with $72 \%$ of the general population. ${ }^{3}$

On February 6 2001, a special election was held to choose only the prime minister; members of the knesset (parliament) did not stand for election.

Around $60 \%$ of eligible voters participated in the elections, a relatively low percentage (in Israel).

In the Abarbanel Mental Health Center, a large psychiatric hospital in the Tel Aviv area, only 132 of the 509 patients hospitalised that day, $26 \%$, voted. If the additional 47 patients released for the day followed past patterns and they voted while at home, the rate of voting among the patients might have reached $35 \%$.

This is a low result in comparison with the general population; however, it is similar to the percentage of participants in the 1999 elections. It follows that the percentage of patient participation in these elections did not fall, but rather remained low, as in the past.

It may be that what this shows is that a constant proportion of patients regard themselves as part of society and want to participate in the vote. On the other hand, it could be that they were detached and uninfluenced by the general frame of mind and ambivalence in society which caused many to refrain from voting in this election.

It is time for all the mentally ill to participate in all the actions of society, including voting.

\section{References}

1 Armstrong B.The mentally disabled and the right to vote. Hospital and and the right to vote. Hospital and

2 Melamed Y, Shamir E, Solomon Z, Elizur A. Hospitalized mentally ill Elizur A. Hospitalized mentally ill patients vote for the first time. Isra
fournal of Psychiatry 1997;34:69-72.

Fournal of Psychiatry 1997;34:69-72.
Melamed Y, Nehama Y, Elizur A. Hos3 Melamed Y, Nehama Y, Elizur A. HosIsrael. The fournal of Forensic Psychiatry 2000; 11:691-5.

DR YUVAL MELAMED Head, Department $5 \mathrm{~A}$

Abarbanel Mental Health Center, Bat Yam,

Lecturer, Tel Aviv University, Faculty of Medicine 